DOI: 10.12957/demetra.2016.22504

\title{
As pequenas bailarinas do baby class: construções do feminino no ensino do balé
}

\section{The little baby class ballerinas: a discussion about gender through ballet}

\author{
Larissa Escarce Bento Wollz',2 \\ Juliana Cecilio Cerqueira² \\ Rita Flores Müller ${ }^{3}$ \\ 1 Universidade do Estado do Rio de Janeiro, \\ Instituto de Nutrição, Núcleo de Estudos sobre \\ Cultura e Alimentação (NECTAR). Rio de Janeiro- \\ RJ, Brasil. \\ ${ }^{2}$ Instituto Oswaldo Cruz, Curso de Especialização \\ em Ciência, Arte e Cultura na Saúde. Rio de \\ Janeiro-RJ, Brasil. \\ ${ }^{3}$ Centro Universitário Augusto Motta - Unisuam, \\ Curso de Psicologia. Rio de Janeiro-RJ, Brasil. \\ Correspondência / Correspondence \\ Larissa Escarce Bento Wollz \\ Iwollz@yahoo.com.br
}

\section{Resumo}

A dança sempre esteve presente na história da humanidade. Na sua forma mais antiga, as danças sagradas foram vivenciadas em diversos rituais. O balé surge mais recentemente permeado de fantasia, romance e misticismo, influenciando a estética do corpo do bailarino e a construção do imaginário da figura da bailarina. O corpo torna-se então um lugar central da dança, seja pelo estudo e análise do movimento, pela beleza da dança ou pelo ideal de leveza e beleza que ele representa. O objetivo do presente artigo é delinear a produção do corpo no ensino do baby class, corpo este atravessado pela gramática binária do gênero na constituição de territórios/práticas femininas e masculinas. Para isso, faz um breve histórico do surgimento da dança e do balé, do clássico ao contemporâneo, para falar deste lugar do corpo na contemporaneidade, no qual a constituição/oposição dos gêneros se faz presente. Apesar de o balé clássico nos dias atuais ser rotulado como uma dança tipicamente/tradicionalmente feminina e os bailarinos serem em maioria mulheres, nem sempre foi assim. E mesmo hoje, em pleno século XXI, ainda há muito preconceito contra meninos que se interessam pela dança e, em especial, pelo balé nas turmas de baby class, demostrando o conservadorismo existente e como os estereótipos de gênero são continuamente reforçados e naturalizados, ajudando então na manutenção do pensamento conservador.

Palavras-chave: Corpo. Dança. Feminino. Masculino. Criança. 


\section{Abstract}

Dance has always been present in the history of humanity. Sacred dances, in their oldest form, have been present in diverse rituals. Ballet has appeared more recently, permeated with fantasy, romance and mysticism, influencing the aesthetic of the ballerina's body and the construction of the image of the ballerina's figure. As a result, the body plays a central role in dance, be it for the study and analysis of movement, for the beauty of dance or for the ideal of the weightlessness and beauty that it represents. The purpose of this article is to outline the body's production in teaching baby class, while this body is crossed by binary grammar of gender in the constitution of territories / female and male practices.This text presents the emergence of dance and ballet, from classical to contemporary, in which the construction of gender makes itself present. Although present-day classical ballet is labeled as a typically feminine dance and the majority of performers are female, it has not always been this way. Even today, in the 21st century, there is still much prejudice that is continuously reinforced and naturalized, helping to maintain these conservative thoughts

Key words: Body. Dance. Gender. Female. Male. Child.

\section{O surgimento da dança e do balé: do clássico ao contemporâneo}

O objetivo do presente artigo é delinear a produção dos corpos no ensino do baby class, corpos estes atravessados pela gramática binária do gênero na constituição de territórios/práticas femininas e masculinas. Marcados pela história, tanto o corpo quanto a dança são locus de nosso olhar em sua relação com o feminino e, mais contemporaneamente, com o ensino do baby class como um espaço ainda marcadamente feminino. Em sua oposição, esse olhar também nos ajuda a pensar em como a prática do baby class por meninos ainda é alvo de preconceito e discriminação de gênero.

A dança sempre esteve presente na história da humanidade. Na sua forma mais antiga, as danças sagradas foram vivenciadas em diversos rituais. Entre cerimônias para reverenciar deuses e pedir sucesso nas caçadas e vitórias nas lutas, a dança acompanhou a evolução humana, transformando seu formato e seus fins. Desde o período Paleolítico, o homem dançou as danças circulares, danças fálicas, danças fúnebres, danças de abraço, mistas - com pares formados de homens e mulheres; dança de galanteio e dança do ventre. "De seu nascimento à morte, a civilização grega é completamente impregnada pela dança. Ritos religiosos, pan-hêlenicos ou locais, cerimônias cívicas, festas, educação das crianças, treinamento militar, vida cotidiana, a dança está presente por toda a parte.”2 
A dança formava um cidadão completo, pois ela daria proporções corretas ao corpo e seria a fonte de uma boa saúde. Além das danças religiosas, os gregos utilizavam as danças como forma de educação para a guerra, treinando seus futuros soldados desde criança. As aulas continham exercícios preparatórios de flexibilidade e exercícios, onde os movimentos eram ritmados por um tocador de flauta. A dança também estava presente em momentos corriqueiros da cultura grega, como nascimento, casamentos e banquetes, que contavam com dançarinas profissionais. É de origem grega a utilização da meia-ponta dos pés - o que mais tarde se firmará como uma das posturas básicas da dança, utilizadas em diversos gêneros, inclusive o balé clássico. ${ }^{2}$

Na Idade Média, a dança sofreu uma ruptura na evolução coreográfica, tornando-se totalmente sagrada, e somente no estabelecimento da cultura leiga é que a dança se tornaria matéria de espetáculos e divertimento. Com a Guerra dos Cem Anos e a epidemia da peste negra no século XIV, a dança macabra (cemitério, originado do árabe makhbar), dançada pelos nobres, representava na morte uma razão para viver de acordo com os princípios cristãos. Mais tarde aparecia um novo gênero que determinaria o balé-teatro, o momo, onde os dançarinos utilizavam máscaras para dançar

Bem estabelecido nas cortes de príncipes do século XV, o momo já adianta elemento do balé de corte que irá se desenvolver cem anos mais tarde: dançarinos, cantores, músicos, carros, efeitos de maquinaria. Mas falta-lhe a alma do espetáculo: a ação dramática coordenada. ${ }^{2}$

No Renascimento italiano, surgiu o quattrocento, ${ }^{\text {a }}$ dança que se tornaria uma arte erudita em que os dançarinos não só precisam saber os passos como também entender sobre métrica. É nesse contexto que surge, pela primeira vez, o bailarino profissional, caminhando para um tipo de técnica da dança. Domenico da Ferrara, o primeiro grande mestre desse tipo de dança, publicou uma obra na qual organizava os elementos principais do quattrocento: métrica, comportamento, memória, percurso e aparência. A dramática escolha do homem entre a fé e a razão serviu de alimento para a dança no começo do período renascentista, retirando aos poucos a dança do lugar sagrado imposto pelo período da Idade Média. ${ }^{2}$

Apesar de ter sofrido influências do renascentismo italiano, foi na França que surgiu o ancestral do balé clássico, o balé de corte. Com o contexto europeu, de sucessões políticas e guerras, na segunda metade do século XVI, o balé de corte fora criado para afirmação do poder real trazendo paz e propaganda para os grandes nobres, após o estabelecimento da autoridade real o balé se configurou para afirmar a monarquia e um meio de adulação da pessoa do rei. Segundo Bourcier, ${ }^{2}$ o balé de corte era em primeiro lugar um baile organizado em meio a uma ação dramática, com

a Eventos culturais e artísticos realizados na Itália no século XV. Foi uma fase de transição entre o final da Idade Média e o começo do Renascimento no campo das artes. 
os bailarinos formavam configurações geométricas: círculos, quadrados, losangos e retângulos (pois os balés eram concebidos para serem visto do alto), e com enredos inspirados na mitologia.

No período barroco o balé de corte continuava sua vasta produção no reinado de Luiz XIII, que além de apreciar os balés ainda atuavam neles. Os balés desta época ganham um tom burlesco, onde a dança misturada a outras artes como teatro, circo e pantomima etc., exibia um grande tom cômico nas peças. A partir de 1600, o balé de corte, que era monopólio da corte da França, passou a ser visto na Itália, na Inglaterra e espalhando as cópias francesas pela Europa. A morte de Luiz XIII marcou não só um fim de uma sociedade como também o do balé de corte, e esse gênero da dança estava ultrapassado e se buscava tanto uma nova formula de espetáculo, quanto uma nova técnica de dança. "Apenas trinta anos foram necessários para que um mestre do gênero, Pierre Beauchamps, conseguisse definir o essencial a essa técnica”. ${ }^{2}$

\section{0 surgimento do balé clássico}

O balé clássico tem seu nascimento na renascença italiana, no século XVI, mas foi levado para a França e consagrado como gênero da dança em 1581, o Ballet Cominique de La Reine. Encomendado a Balthazar de Beaujoyeux ${ }^{\mathrm{b}}$ por Catarina de Medici para o casamento de sua irmã, foi o balé mais completo visto até então. Apesar de o balé clássico ter em suas origens a cultura camponesa, ele se com consolidou como hábito da elite, pois os nobres acreditavam que ele serviria para educar o corpo conforme seus padrões de etiquetas e gestuais. ${ }^{2}$ Com o reinado de Luiz XIV, o balé sofreu grande desenvolvimento no século XVII. Considerado pai do balé clássico, além de bailarino mantinha uma paixão pela arte que o levou a investir na profissionalização do balé com a criação da Académie de Royal de Danse (atual Ópera de Paris). Com a criação da academia, foi possível desenvolver gestuais de cabeça, tronco, braços e pernas que fundamentariam a normatização da dança clássica.

O balé foi introduzido na ópera por Jean Baptiste Lully, que empregava a dança como divertimento no intervalo entre os atos da ópera. Com personagens mitológicos enfrentando aventuras amorosas, ópera-balé ainda se mantinha no círculo limitado da alta sociedade. Na sua forma de apresentação e nos figurinos o ópera-balé, ainda estava muito ligado às heranças do balé de corte, porém muitos mestres apontariam as mudanças necessárias para que a dança clássica pudesse evoluir. Na publicação de Raoul Auger Feillet, intituladac "A coreografia ou a arte de descrever a dança por caracteres, figuras e sinais demonstrativos através dos quais se aprendem facilmente por si mesmo todos os tipos de dança", de 1699, são transcritos mais de quatrocentos passos da técnica

b Nome artístico do francês Baldassarino da Beldioso.

c Título original: La Choréographie ou L'Art de décrire La danse par Caracteres, Figures et Signes Dèmostratifs avec Lesquel on Apprend Facilement de Soy-meê toutes Sortes de Danse. 
do balé. Segundo Bourcier, ${ }^{2}$ é a primeira tentativa de notação de dança, indicando posição inicial dos pés, saltos e passos que serviriam para a normatização da técnica clássica.

No século XIX, La Silfide deu início à fase romântica do balé. Com enredo sobre um amor idealizado entre um ser mortal e espiritual, retratava a oposição entre mundo material e imaterial. Marius Petipa transformou todo o conteúdo dos balés, utilizando contos infantis, e conseguiu unir essas histórias à técnica clássica, resultando em enredos poéticos e dramáticos. A Bela Adormecida, Dom Quixote e Lago dos Cisnes, balés de Petipa, assim como Gisele, Coppélia, Cinderela e o Quebra-Nozes, de outros coreógrafos, traziam a magia de príncipes e princesas, fadas, sílfides e bonecas permeadas pela dificuldade de vivenciar seus amores. ${ }^{2}$ Típicos enredos românticos, esses balés fascinaram tanto o público, que são remontados até os dias atuais. Com títulos famosos, a fase romântica inspirou muitos conceitos que serão abordados neste trabalho. Permeado de fantasia, romance, misticismo, o balé romântico influenciou a estética do corpo do bailarino e a construção do imaginário da figura da bailarina.

\section{A construção do corpo}

O dicionário Aurélio define corpo como "tudo que ocupa espaço, constituindo-se de uma unidade orgânica", mas os múltiplos significados que permeiam a corporeidade vão além da existência biológica do corpo, que compreende todos seus aspectos: o físico, o fisiológico, o corpo orgânico, os códigos sociais, o corpo inter-relacional,o corpo da cultura, o corpo sutil da dimensão espiritual, etc. Para estudar esse assunto, é preciso levar em consideração cada uma dessas características, entendendo que o corpo se estabelece numa plenitude, na qual todos os elementos citados acima são indissociáveis e responsáveis pela construção da identidade do sujeito. ${ }^{3}$

É através do corpo que o indivíduo experimenta o mundo, vivencia sensações e se comunica na sociedade. Mauss ${ }^{4}$ declara que o corpo é moldado pelo meio que habita ao mesmo tempo em que o corpo influencia esse ambiente. Analisando as ações simples do dia a dia, como andar, sentar e comer, por exemplo, é possível verificar que cada comunidade possui suas especificidades, mesmo nos hábitos mais corriqueiros. Isso se dá pelo fato de a cultura formatar alguns códigos que são perpassados durante as experiências e vivências do sujeito em seu meio. Esses códigos são tão específicos que se pode observar que uma mesma sociedade possui gerações que executam seus hábitos de maneira distintas.

No contexto social atual, essa percepção fica mais clara por conta da velocidade dos avanços tecnológicos e as constantes modificações no estilo de vida do homem. Uma geração é ensinada com determinados valores e hábitos que pouco tempo depois se tornam obsoletos e precisam ser reaprendidos. Segundo Mauss, ${ }^{4}$ mesmo numa mesma sociedade, uma geração difere da outra. Isso pode ser facilmente observado em algumas gerações, que apresentam dificuldades com o novo 
estilo de vida inundado por tecnologia e máquinas. Isso não se dá só por conta da idade em si, mas por toda uma construção de técnicas, valores e tradições que permeiam o corpo desses indivíduos e que de repente não servem mais. Mais que aprender a viver com a tecnologia, essas pessoas precisam desaprender parte de seus experimentos e conhecimentos para adquirir o mais atual.

A cultura desenvolve no sujeito valores e princípios que são incorporados na construção da identidade. Segundo Ferreira, ${ }^{5}$ os padrões culturais atuam como organizadores de símbolos e signos de cada cultura que, com suas especificidades, estabelecem seus códigos de pertencimento e reconhecimento, criando um ambiente para o sujeito construir sua identidade e suas relações. Aprendendo esses códigos, o indivíduo consegue se expressar e entender, estabelecendo a comunicação com os outros e com o mundo, o que é primordial para a construção de sua identidade, pois o homem é um ser social. Através de seus gestos, expressões e hábitos, o corpo vai sendo inscrito dialogando com quem ele é, com sua cultura e sociedade.

Segundo Mauss, ${ }^{4}$ as técnicas corporais atuam por meio da reprodução, de forma consciente ou não, na qual o sujeito imita os trejeitos de pessoas que ele julga bem-sucedidas em determinada área. Assim, o indivíduo não cria seu próprio gestual, mas incorpora ao seu corpo várias características de outras pessoas que reconhece como autoridades em algum assunto, por admirá-las, ou por esperar obter o mesmo sucesso que elas.

Nos dias atuais, com a tecnologia no campo da informação, isso acontece em grande escala. Por meio de blogs, vídeos e fotos, indivíduos se tornam referências em diversas áreas como moda, alimentação, atividade física e saúde, criando um público de seguidores não só do seu conteúdo, mas também nos modos de falar e gesticular, influenciando a corporeidade de centenas, dezenas e muitas vezes milhões de espectadores.

Na cultura ocidental, os meios de comunicação apresentam modelos estéticos que difundem um corpo idealizado que se tornou um padrão cultural a ser seguidos por todos. O panorama atual encara o corpo como um objeto, e o indivíduo, ao invés de ser um corpo, tem um corpo.

A visão de objetivação do corpo faz parte de um conceito moderno de corpo, que traz consigo uma nova forma de observar o indivíduo na sociedade atual. Nessa visão o sujeito, ao invés de se relacionar com o outro, tende ao isolamento, preferindo uma experiência corporal individual a uma coletiva. O corpo é visto como uma parte do homem dissociada dele mesmo, sendo considerada uma máquina que apenas executa funções. ${ }^{6}$ Nos contextos atuais, o sujeito submete seu corpo a treinamentos, de forma a adestrar seus hábitos, para alcançar os padrões culturais impostos ao corpo na sociedade. Desta forma, pode-se observar que o processo de inscrição no corpo está sempre em movimento em um processo de constante mudança. Segundo Turtelli, ${ }^{7}$ a imagem corporal engloba tanto o lado cognitivo do indivíduo quanto suas memórias, intenções, desejos e experiências. Com caráter múltiplo, os aspectos emocionais e fisiológicos se integram com as vivências do indivíduo, integrando o eu do passado no presente e resultando numa nova imagem corporal. ${ }^{8}$ 
Le Breton ${ }^{6}$ afirma que os meios social, cultural, relacional e pessoal são responsáveis pela construção da imagem corporal do sujeito. O corpo se adapta aos contextos sociais no qual se insere, expressando uma maneira particular de perceber o mundo de cada sujeito, justificada pelas marcas de sua vivência, que é a construção de sua imagem corporal e sua identidade. Além desse caráter individual, a imagem corporal se reflete na coletividade, nas relações pessoais e familiares, nos afetos e na visão segundo a qual o sujeito interpreta o mundo, o outro e si mesmo. ${ }^{5}$ Por meio dos contatos de seus corpos e experiências, acontecem trocas de vivências entre os indivíduos, e assim as imagens corporais vão sendo doadas e agregadas. Nas interações sociais, o indivíduo observa semelhanças e diferenças em relação ao outro e vai aprendendo sobre si, criando sua própria identidade.

Para Turtelli, ${ }^{7}$ o contato entre as relações do indivíduo acontece por meio do movimento. O poder de comunicação do corpo faz com que a dança seja uma das linguagens de artes que estabelece um contato com seus espectadores sem palavras, somente com o gestual do bailarino. André ${ }^{9}$ explica que a arte do corpo é a vivência de afeto, prazer, dor, desejo, memória e linguagem do sujeito quando o corpo se empresta à arte. Como um núcleo de energia onde as estruturas conscientes e inconscientes se estruturam e se desestruturam, a dança não só é a arte produzida através do corpo como o corpo é a própria arte. O bailarino em cena não só executa passos da coreografia do personagem, mas está contaminando a obra com suas vivências e experiências particulares inscritas em seu corpo, tornando-se co-criador da obra. Ao dançar, o sujeito bailarino abre possibilidades para ser múltiplos sujeitos que se transforma em movimento por meio desse corpo que é objeto e espaço, que é sentido e vivido, que é infinito e efêmero.

\section{O feminino no balé clássico}

Apesar de o balé clássico, nos dias atuais, ser rotulado como uma dança tipicamente feminina e os bailarinos serem em maioria mulheres, nem sempre foi assim. Como uma arte que ultrapassa séculos, o balé passou por diferentes tipos de sociedade, o que refletia diretamente o modo como se dançava. No início da construção do balé clássico, segundo Assis \& Saraiva, ${ }^{20}$ os homens eram unânimes na dança, inclusive quando se tratava de interpretar papéis femininos, eles se travestiam e interpretavam personagens de mulheres, pois as mulheres não podiam atuar, só assistir. Somente no século XVII, com o começo da profissionalização do balé, é que se deu a inclusão das mulheres nesta arte, mais precisamente em 1681, com Mademoiselle Lafontaine, que inaugurou o balé como arte para ambos os sexos (Aquino e Saraiva apud Siqueira, 2012).

A revolução industrial francesa, do século XVIII ao XIX, caracterizou-se pela baixa participação dos homens na dança, pois o corpo passou a ser visto como instrumento de produção, e com a desvalorização da dança nesta época, os homens procuraram trabalhos com melhor remuneração. Esse panorama foi favorável para as mulheres que começaram a se destacar nas apresentações, 
embora algumas bailarinas fossem taxadas como prostitutas, pois aceitavam ofertas de homens ricos, por não conseguirem se destacar na carreira da dança. ${ }^{20}$

No período do balé romântico, a mulher alcançou o auge de sua importância, tornando-se o personagem principal nos enredos. Aquino \& Schawart ${ }^{21}$ afirmam que a mulher deixou de ter uma imagem de pagã e passou a ser vista como um ser angelical, figura atrelada a pureza, beleza, delicadeza. Segundo Almeida, ${ }^{22}$ foi nesse mesmo período que os homens começaram a interpretar papéis secundários no balé. Essa característica é bastante explícita no momento do pas de deux, ato em que o homem e uma mulher fazem um dueto de dança, cuja coreografia é construída de forma que o bailarino esteja ali para dar suporte e apresentar a sua partner, que é a estrela principal da cena.

É no século XVIII também que as vestimentas das bailarinas começaram a se modificar, figurinos mais curtos e mais leves, possibilitando o aparecimento das sapatilhas, e uma evolução da técnica do balé clássico. Lopes ${ }^{23}$ afirma que a mudança na vestimenta pode ser vista como um ponto de liberação feminina, pois na corte francesa e italiana, as mulheres eram obrigadas a dançar com figurinos pesados e saias compridas, sem condição de realizar movimentos ágeis. Por isso, as coreografias desse momento no balé eram realizadas em grupos com desenhos geométricos, com pequenas movimentações de mãos e braços. As saias só foram encurtadas em 1721, pela primeira bailarina Marie Camargo.

O período romântico do balé revelou fascínio pelo sobrenatural, fantasia e pelos mistérios da mente. Através de história de contos de fadas e romances melodramáticos, os coreógrafos buscavam magia em detrimento do aspecto racional, exaltando a mulher não na sua condição natural de mãe, esposa ou amante, mas na representação de um ideal sonhado. ${ }^{20}$ No momento em que Maria Taglioni subiu nas sapatilhas de ponta, o que mais tarde viria a se tornar o elemento simbólico que caracteriza a dança clássica, estabeleceu-se o auge da mulher no balé, pois essa proeza só era reservada às mulheres. Tanglioni passou a ser referência de bailarina, não só pelo seu corpo de sílfide, mas também como figura feminina, por inúmeras bailarinas idealizando uma tendência à idolatria da feminilidade no balé.

Almeida ${ }^{22}$ afirma que existem diferenças quanto ao gênero na técnica clássica. Enquanto a bailarina possui uma imagem na magreza, leveza e ser etéreo, caracterizada pela técnica de sapatilhas de pontas, na saia tutu, no equilíbrio, no giro e nos grandes saltos das coreografias, o bailarino precisa demonstrar em seus movimentos, força e agilidade na condução da bailarina na dança. Hoje, o balé permeia um universo de princesas e sílfides, tendo como personagem principal mulheres delicadas, amáveis, belas, graciosas, carregado de elementos arquetípicos. ${ }^{23}$ Com histórias baseadas em contos de fadas e no mundo irreal, ele é apreciado e entendido por diversas pessoas independentemente de etnia, classe social e idade. Talvez por isso os balés de repertório e a imagem da bailarina encantem tanto as crianças desde a primeira infância. 


\section{A construção do corpo da bailarina}

As artes possuem uma forma singular de comunicar sentidos e percepções de mundo, seja nas artes plásticas, na música, no teatro ou na dança. O corpo está intimamente correlacionado com os processos artísticos - afinal, todo artista se utiliza dele para realizar sua obra. Segundo Tércio, ${ }^{10}$ o corpo recepciona os objetos artísticos, encontrando-se no centro do fenômeno de fazer arte. Quando se trata da dança, o corpo não só faz parte do processo de fazer arte, como também se transforma na obra artística. André ${ }^{2}$ afirma que o corpo do bailarino não pode ser visto somente como objeto de arte ou resultado de uma coreografia; suas vivências estão inscritas nesse corpo.

O bailarino empresta seu corpo para a arte, ele não só executa os passos, mas também contamina a obra com sua história, tornando-se um co-criador. José Gil, citado por Tércio, ${ }^{10}$ afirma ainda que o corpo do bailarino exerce sobre os espectadores um certo deslumbramento, que é decorrente do ato de dançar e da invisibilidade do espaço dançado; o corpo do bailarino está emprestado ao personagem e ao mundo. Na dança, há um espaço virtual que transcende o espaço exterior do corpo; o bailarino atua na construção, desconstrução e reconstrução do seu interior e do exterior do seu corpo.

Apesar de cada pessoa possuir suas características físicas, no ambiente da dança existem certos estereótipos corporais que são justificados pela técnica específica para cada estilo de dança, muitas vezes justificando na técnica o padrão corporal. No jazz dance, por exemplo, é considerável que a bailarina possua coxas grossas, cintura fina, o biótipo "sarada" que hoje tanto vemos. Já na dança contemporânea, por se tratar de uma técnica que visa experimentação do seu próprio corpo, qualquer biótipo é bem-vindo. O gênero de dança mais rígido nesse sentido, talvez pela sua idade de existência, é o balé clássico, que exige um tipo físico bem especifico, o que é chamado de ectomorfo. ${ }^{11}$

Temos então três tipos de corpos: o endomorfo, mesomorfo e ectomorfo. As pessoas com o tipo de corpo endomorfo apresentam mais gordura corporal, são pessoas com ossos largos, quadris e coxas grandes e rostos redondos, braços e pernas curtos; normalmente têm cintura alta, e mãos e pés pequenos. $\mathrm{O}$ mesomorfo possui um metabolismo acelerado e corpo atlético, corpo magro, com cintura baixa, estreita e ombros largos, mandíbula quadrada e maçãs do rosto proeminentes; por conta do seu metabolismo, possuem grande facilidade de perder peso e ganhar massa muscular. As características do corpo ectomorfo são pessoa com aparência extrema magra, com ombros, cintura e quadris estreitos, rosto triangular, dificuldade de ganhar massa muscular e com baixo nível de gordura corporal. ${ }^{11}$

O tipo de corpo da bailarina é o ectomorfo, caracterizado pelo corpo longilíneo, magro e leve. Segundo Anjos, ${ }^{11}$ esse formato de corpo vem como herança do balé romântico, do século XIX, que tinha a imagem de sílfide - bailarinas magras, franzinas, com aspecto frágil -cujo objetivo 
era mostrar a pureza do personagem. Segundo Moura: ${ }^{12}$

Bailarinas fantásticas, que em cena, jamais, podem revelar o esforço necessário para concretizar todas aquelas proezas que seus corpos maravilhosos realizam. Estética enganosa, de faz-de-conta, porém extremamente agradável aos sentidos.

Nessa época, Marie Taglione, que ficou conhecida no balé La Sylphide, tornou-se um referencial de bailarina clássica.

O biotipo da bailarina vem ultrapassando séculos e diferentes culturas, e por mais que o balé clássico não seja mais uma arte voltada para a elite francesa, sua globalização não quebrou o padrão corporal da sílfide, que é buscado e venerado por quem dança. Esse panorama pode ser influenciado pela reprodução dos balés românticos, os chamados balés de repertório, como já foi dito, o que pode justificar a procura por esse corpo magro e frágil, ainda nos dias atuais. O padrão de corpo das bailarinas ainda é baseado no corpo euro-americano, sem muitas curvas e longilíneo, com membros alongados e finos, que corresponda ao estereótipos da bailarina romântica europeia, que seja uma sílfide, uma fada, uma princesa, leve, graciosa, magra, jovem, que tenha disciplina e determinação para fazer o sacrifício de ajustar seu corpo a essas regras.

$\mathrm{Na}$ pesquisa de Anjos ${ }^{11}$ com bailarinas e professoras de balé clássico, estas conseguiram identificar, com base nos relatos de entrevistas, que as bailarinas mostravam grande preocupação com sua eficiência na funcionalidade corporal. Esse estudo apresenta o corpo da bailarina clássica como três alicerces: a anatomia, a técnica e a expressão - um conceito chamado de "tríade do corpo da bailarina clássica”. Segundo esse conceito, a anatomia ideal da bailarina seria com as pernas e braços longos, com boa rotação de endehors, hiperextensão das pernas, colo do pé acentuado, meia ponta de pé alta, além de força muscular, equilíbrio e coordenação motora. Essas características são vistas no meio do balé como tesouros, e as bailarinas que não as têm, buscam-nas incessantemente.

Essa parte da esfera, segundo Anjos, ${ }^{11}$ está associada à condição do sujeito, somada às características corporais determinadas pela cultura do balé. Segundo Hass, ${ }^{13}$ o padrão estético muitas vezes leva as bailarinas a distorções sobre a imagem corporal. No seu estudo, as bailarinas entrevistadas se encontravam insatisfeitas com seu corpo, mesmo tendo um corpo magro e baixo percentual de gordura corporal. Essa construção do corpo excessivamente magro pode ser prejudicial em muitos sentidos, levando as bailarinas a transtornos alimentares, baixa autoestima e problemas emocionais graves. É fundamental conscientizar professores e alunos de que cada um possui uma estrutura anatômica que vem da sua genética, mas que mesmo que não tenha essa parte da tríade, com a técnica podem dançar eficientemente.

O segundo nível da esfera, segundo Anjos, ${ }^{11}$ está no âmbito da vontade, daquilo a que o sujeito se dedica intencionalmente por desejar, pois é por meio da técnica que se consegue moldar o corpo 
para melhorar o desempenho no balé. É através dela que a bailarina aumenta sua flexibilidade, ganha força muscular e aprende os exercícios corretamente. Desta forma, desenvolve um bom desempenho nos palcos, conseguindo executar os passos com destreza e de maneira precisa, encantando os espectadores com a dança.

A terceira e última parte da tríade, a essência, que também pode ser chamada de "dançar com a alma”, é a capacidade de atuar com sensibilidade artística. Segundo a pesquisa de Anjos, ${ }^{11}$ a essência está na parte subjetiva da esfera, é dita como inata a quem dança; as bailarinas já nascem com ela, e não é possível construir essa característica, pois não se pode mensurar como isso pode ser ensinado. É a essência que separa a dança das outras atividades físicas, pois o movimento do dançarino tocará o espectador, emocionando e sensibilizando com sua interpretação do personagem em cena.

\section{0 baby class e 0 ensino da feminilidade}

O ensino da técnica clássica, segundo Caminada \& Aragão, ${ }^{1}$ se inicia a partir dos sete anos de idade, na primeira fase do nível básico do balé, denominado "preliminar". Nesse estágio, a criança começa a aprender os fundamentos básicos da técnica, como o endehors, as cinco posições dos pés, as posições de braços, os arabesques e allongés, com a aula sendo dividida em barra, centro e diagonal.

Apesar de a iniciação da técnica ser recomendada a partir dos sete anos, existem hoje turmas de balé para crianças mais novas, tanto nas academias de dança, como nas escolas de ensino formal. Esse novo panorama pode ter sido modificado nas últimas décadas em virtude de a criança chegar cada vez mais cedo no ambiente escolar. A própria Lei de Diretrizes e Bases alterou a iniciação obrigatória da educação infantil de cinco para quatro anos de idade, e com certeza esse fator tem influenciado a estrutura do ensino do balé clássico infantil.

As turmas anteriores ao estágio preliminar do ensino do balé são chamadas de baby class e abrangem as crianças de dois aos seis anos; podem ser denominadas também de "turmas de iniciação à dança”. Segundo as teorias de desenvolvimento infantil de Piaget, ${ }^{24}$ cada fase é caracterizada por formas diferentes de organização mental, e faz-se necessário o entendimento de cada uma delas para que se possa entender a criança e a forma de estimular e desenvolver suas habilidades.

No balé preliminar, a criança se encontra no período das operações concretas, que vai de sete a 11 anos de idade. Nesse período, a criança tem a capacidade de estabelecer relações, interiorizar suas ações, raciocinar de forma lógica, e ter a noção de massa, líquido e quantidade. ${ }^{24}$ Já no baby class, que envolve crianças dos dois aos seis anos, as crianças se encontram no período préoperatório, tendo como principal aspecto a iniciação à linguagem. Segundo Terra, ${ }^{24}$ "a emergência da linguagem acarreta modificações importantes em aspectos cognitivos, afetivos e sociais da 
criança”, pois esta passa a se comunicar com o outro e tal interação lhe permitirá desenvolver novas capacidades, como a construção de esquemas mentais, o pensamento egocêntrico e a inteligência simbólica ou representativa.

O cenário do baby class como iniciação ao balé infantil é relativamente novo, o que justifica ainda não haver uma institucionalização com regras e normas semelhantes aos outros níveis do ensino do balé. Como toda área, no início o que há são metodologias de profissionais do campo com base em pesquisa e estudos por eles realizados, bem como suas experiências em lecionar o balé para esse público em especial.

Bartolo ${ }^{25}$ desenvolveu o método Prima Ballerina, que tem como objetivo ensinar o balé de forma lúdica, possibilitando a criança o aprendizado do autocontrole, limites, independência, autoestima, alívio de tensões e frustrações; criatividade através do universo de faz de conta e refinamento e destreza dos movimentos, despertando sua inteligência. Esse método, segundo sua autora, está fundamentado na pedagogia, na psicologia, na neurociência e na psicomotricidade. Esta última, em especial, tem contribuído e muito para o ensino dessa faixa etária específica, pois contribui na formação do indivíduo com o objetivo de incentivar a prática do movimento em todas as etapas do desenvolvimento infantil.

A psicomotricidade, segundo Alves, ${ }^{26}$ compreende os homens no âmbito psíquico - desenvolvendo os aspectos sociais, afetivos e cognitivos; e no âmbito da motricidade - desenvolvendo a base neurofisiológica e ampliando a capacidade de movimentação do corpo. É, portanto, uma ciência que estuda o homem através de seu corpo na relação com o mundo interno e externo.

Ela se divide em dois conceitos principais - o relacional e o funcional. Os conceitos relacionais facilitam a relação entre os indivíduos e seus corpos através dos desejos, das frustrações e das ações. Já os conceitos funcionais são as possibilidades percebidas através da ação e da qualidade de movimentos. Os conceitos funcionais se dividem em diferentes áreas do desenvolvimento motor, como: coordenação, postura, tônus, equilíbrio, respiração, lateralidade, orientação e estruturação espaço-temporal; ritmo, percepções e esquema corporal.

Oliveira ${ }^{27}$ explica que a psicomotricidade aplicada ao ensino do balé infantil dá oportunidade de a criança se desenvolver de forma integral, possibilitando a tomada de decisões, identificando-a como ser produtor de arte, cultura, proporcionando o reconhecimento do seu corpo no mundo.

Alves $^{26}$ afirma que o conceito funcional responsável por formar a personalidade da criança e equilibrar suas funções psicomotoras e maturacionais é o esquema corporal. É através dele que a criança começa a perceber o mundo externo e toma consciência do seu corpo. A autora explica que a criança de início não diferencia os objetos que a rodeiam, mas conforme vai crescendo, apreende que seu corpo ocupa um espaço em função do tempo, sendo capaz de captar imagens e aguçando sua percepção quanto a cheiros, sabores, sons, dor e movimentos. O esquema corporal 
abrange o conhecimento intelectual sobre as partes e funções do corpo, o reconhecimento sobre a posição dos músculos e partes do corpo e a representação visual do corpo - ou seja, a impressão que o indivíduo tem de si mesmo.

No ensino do baby class, o esquema corporal é explorado em toda sua amplitude, na percepção quanto a sons e movimentos, na descoberta da colocação do corpo no espaço, e sobretudo na compreensão da imagem da bailarina, por se tratar de uma arte que se fundamenta na estética e no virtuosismo. Para Souza, ${ }^{28}$ a ludicidade deve estar em todos os momentos da aula de balé infantil, nas músicas, nos exercícios e na condução da aula, principalmente na faixa etária do baby class. Através do ensino do balé de forma lúdica, a criança constrói conceitos lógico-matématico e sociais, segundo Bartolo ${ }^{25}$. Como recurso da ludicidade, os contos de fadas, que permeiam o universo infantil feminino, são utilizados em aula. Princesas, fadas e a própria imagem da bailarina romântica, com o biótipo de sílfide, vestida de tutu e sapatilha de pontas, são exploradas no ensino do balé infantil para o aprendizado dos aspectos de leveza e graça característicos da técnica.

Para Santos, ${ }^{29}$ a vinculação do ensino do balé a princesas e fadas se dá pelo princípio do aplomb, ${ }^{\mathrm{d}}$ e por mais que se busquem outros tipos de alusões a serem trabalhadas nas aulas, as crianças não correspondem tanto quanto são utilizadas as imagens de contos de fadas. Segundo a mesma autora, a prática do baby class pode levar ao aprendizado simultâneo da técnica clássica, como também do modo de ser menina. A pesquisa da autora explica que o balé ainda é visto como uma arte tipicamente feminina e, portanto, relacionado à feminilidade. Por isso, ainda hoje as aulas de balé infantis são quase que exclusivamente frequentadas por meninas, o que reforça no cenário infantil o estereótipo da bailarina na dança clássica.

Muitos dos balés de repertório não só trazem a ideia dos contos de fadas, mas são baseados nos próprios contos. O Quebra Nozes, A Bela Adormecida e Lago dos Cisnes são alguns exemplos de obras clássicas criadas pelo mâitre francês Mairus Pepita. Santos ${ }^{29}$ revela que o professor de balé infantil deve ter cuidado ao seguir pelo caminho dos estereótipos e dos arquétipos femininos, visto que as crianças já sofrem as influências midiáticas sobre a construção e o papel que cada gênero deve possuir na sociedade. Criamos, assim, o modelo de que existe um só modo de ser feminina e de ser bailarina. Como estratégia, Santos ${ }^{29}$ sugere aos professores que sejam trabalhados também balés contemporâneos que não possuem embasamento nos contos de fadas, para não limitar o ser menina à ordem do discurso de gênero como sendo criada para ser uma boa mãe, um objeto heterossexual desejável, ser uma profissional competente, sendo a verdadeira mulher multitarefa.

O balé, como arte essencialmente estética, enaltece a forma, a beleza, a graça e leveza, e inclusive um corpo mais adequado para a técnica clássica. Com a tríade "corpo expressivo", "corpo técnico"

d Aplomb é uma característica que todo bailarino clássico deve ter, significa altivez, aprumo, elegância de movimentos, harmonia no modo de dançar do bailarino. 
e "corpo anatômico", foi possível traçar características do corpo da bailarina clássica, e com a história do balé foi possível compreender por que ele vem sendo vinculado ao gênero feminino, apesar de, em seus primórdios, ter sido dançado somente por homens, inclusive quando se tratava de papéis femininos. No ensino do balé infantil, demonstrou-se através dos estudos que seu ensino pode levar a criança ao aprendizado em toda sua integridade, nos aspectos motores e afetivos, fundamentados em várias ciências, sobreutdo na psicomotricidade.

No período de iniciação a dança, que nos dias atuais tem-se dado mais cedo por vários fatores, crianças de dois a seis anos começam suas aulas na turma de baby class, onde a técnica clássica é ensinada de forma lúdica. Faz-se necessário que o professor de baby class tenha um novo olhar no momento de lecionar o balé infantil, tendo o cuidado de mediar as aulas utilizando vários tipos de referenciais, e não somente aqueles relacionados ao universo dos contos de fadas e balés de repertório. Desta forma, pode-se ensinar a técnica clássica e a feminilidade para as meninas nas aulas de baby class, assim como os aspectos de aplomb, graciosidade e leveza característicos do balé, mas sem gerar cobrança e o estigma nas alunas, trabalhando várias formas estéticas de beleza e der ser bailarina.

Mas, infelizmente, os estereótipos de gênero são continuamente reforçados e naturalizados nesta atividade "feminina" e, mesmo que haja o interesse dos pais em colocar um menino numa dessas turmas, sabemos que a pressão social para manutenção dos modelos tradicionais é grande. Torna-se um peso muito grande para o menino que simplesmente gosta de dançar e para a família que terá que bancar o ônus do preconceito. São valores naturalizados que quase se confundem com a ordem da natureza, mas são forjados na ordem da cultura, visando a preservação e conservação "dos valores e dos bons costumes".

\section{Considerações finais}

É inegável que o ensino da dança pode levar a criança ao aprendizado em toda sua integridade, nos aspectos motores e afetivos, independentemente do gênero, mas a coerção social fala mais alto e talvez tenhamos que esperar um intervalo de tempo maior do que o de uma geração para olhar com naturalidade para uma turma de meninos no baby class. Mas também é interessante notar que meninas, cada vez mais, atuam em esportes antes considerados masculinos, como o futebol e o skate, sem que isso coloque em questão sua feminilidade. Por que será então que o inverso não é tratado da mesma forma?

As discussões sobre gênero como campo teórico interdisciplinar têm-se difundido ao longo da história por inúmeros motivos. O deslocamento do feminino em direção à igualdade e à paridade de direitos produziu cisões na sólida hegemonia masculinista. As transformações provocadas pelos movimentos feministas, a saída da mulher do privado para o público, sua alçada de mulher-mãe 
à mulher-sujeito, a crise da forma burguesa da família nuclear, monogâmica e heterossexual, a separação da sexualidade da reprodução, uma política de visibilidade da homossexualidade e, ainda mais recentemente, as modificações corporais e nominais realizadas por transgêneros, transexuais e intersexuais, são horizontes de possibilidades que situam o fortalecimento desse campo de estudos, pesquisas e ações. ${ }^{30}$

Diversos autores e autoras realizam pesquisas para compreender o cenário que a cultura propõe, relacionando valores aos modos/modelos de ser mulheres e homens na sociedade. Finco (2003) conceitua "gênero" como sendo uma construção social dentro da cultura, instituindo o que é feminino e masculino. Em um dos textos mais conhecidos no campo - Gênero: uma categoria de análise histórica -, Joan Scott ${ }^{15}$ afirma que: "gênero pode ser entendido como um elemento constitutivo das relações sociais fundadas sobre as diferenças percebidas entre os sexos. É uma primeira forma de dar significado às relações de poder".

Bento $^{16}$ afirma que a construção da identidade de gênero se inicia no período da gestação. Os pais fantasiam quem a criança será e as expectativas são inúmeras. A descoberta do sexo torna um corpo que era absolutamente abstrato em concreto, mesmo com o bebê ainda na barriga da mãe. A criança deixa de ser um bebê e passa a ser uma menina ou um menino. Assim, o sexo na infância se torna fator determinante, marcando uma identidade na decoração do quarto, nas suas roupas e nos seus brinquedos. Graciano ${ }^{17}$ alega que os adjetivos femininos e masculinos são associados diretamente ao sexo biológico. De acordo com essa teoria, ser mulher seria sinônimo de ser feminina, e de forma antagônica, ser homem significaria ser masculino. Além disso, ser homem significaria especialmente não ser uma mulher, numa alusão direta à construção da masculinidade e da virilidade pautadas no repúdio aos signos femininos e à homossexualidade (Welzer-Lang, 1991).

Na escola, a criança vai restringindo seu corpo, conforme sua vivência, inscrevendo nele os moldes comportamentais ditados ao seu gênero. Louro ${ }^{18}$ aponta:

Alise aprende a olhar e a se olhar, se aprende a ouvir, a falar e a calar; se aprende a preferir. Todos os sentidos são treinados, fazendo com que cada um e cada uma conheça os sons, os cheiros e os sabores "bons" e decentes e rejeite os indecentes; aprenda o que, a quem e como tocar (ou, na maior parte das vezes, não tocar); fazendo com que tenha algumashabilidades e não outras...". 18

Dessa forma, a construção de identidades sofre influências por um padrão de valores e qualidades consideradas específicas de um só gênero. Enquanto a menina deve ser cuidadosa, sensível, tranquila, bela e ter boas maneiras, o menino deve ser corajoso, competitivo, agressivo, perseverante e ter espírito de liderança. ${ }^{19}$ 
Quando as crianças não se encaixam nos rótulos inerentes ao seu gênero e ultrapassam os limites determinados pelo seu sexo, são vistas como anormais ou desviantes da matriz de gênero numa perspectiva foucaultiana. Essa matriz produz como parte do processo de normalização os assim chamados "desviantes", resultando no apontamento para o comportamento ideal e a discriminação por seus colegas e professores, por não seguir o modelo padrão. Essa intolerância pode ser ligada a dois fatores: em um dos casos, pode estar relacionada com a vinculação do comportamento infantil com a sexualidade, e assim interpretando as crianças que possuem atitudes teoricamente do sexo oposto como homossexuais. E numa segunda hipótese, essa intolerância estaria relacionada à ameaça das estruturas sociais, segundo Graciano. ${ }^{17}$

O gênero como constituinte do sujeito está relacionado ao conceito de múltipla identidade, segundo o qual a identidade deixa de ser uma unidade fixa e passa a ter formato móvel. Assim como o gênero, o sujeito é construído da sua etnia, classe, sexualidade, religião, nacionalidade, dentre fatores que o fazem ser quem ele é.$^{19}$ A multiplicidade da identidade tem caráter articulador, transformando e construindo o sujeito conforme suas vivências e experiências.

Será que os meninos estão eternamente condenados a jogar bola e não dançar? Ou será que na geração dos nossos filhos e netos isto já não será mais uma questão? Para terminar, entre nossos amigos e parentes, quais colocariam espontaneamente seus filhos de três anos no baby class?

\section{Referências}

1. Caminada E, Aragão V. Programa de ensino de ballet: uma proposição. Rio de Janeiro: UniverCidade Editora; 2006.

2. Bourcier P. História da dança no Ocidente. São Paulo: Martins Fontes; 2001.

3. Costa VMM. Corpo e história. Revista Ecos 2011; (010):245-258.

4. Mauss M. Tecniques of the body [Internet]. 1935. p. 70-88. [acesso em: 12 abr. 2016]. Disponível em: https://monoskop.org/images/c/c4/Mauss_Marcel_1935_1973_Techniques_of_the_Body.pdf

5. Ferreira FR. The production of meanings regarding body image. Interface - Comunicação, Saúde, Educação 2008; 12(26):471-83.

6. Le Breton D. Antropologia do corpo e modernidade. Petrópolis: Vozes; 2013.

7. Turtelli LS, Tavares MCGCF, Duarte E. Caminhos da pesquisa em imagem corporal na sua relação com o movimento. Rev. Bras. Cienc. Esporte 2002; 24(01):151-166.

8. Barros DD. Imagem corporal: a descoberta de si mesmo. História, Ciências, Saúde 2005; 12(2):547-554.

9. André JM. As artes do corpo e o corpo como arte. Philosophica 2002; 19/20:7-26. 
10. Guimarães DTR. Da autenticidade do corpo na dança [Internet]. In: Rodrigues D, editor. O corpo que (des)conhecemos. Lisboa: FMH edições; 2005. p. 49-63. [acesso em: 12 abr. 2016]. Disponível em: http://docplayer.com.br/8447382-Da-autenticidade-do-corpo-na-danca-daniel-tercio.html

11. Anjos KSS, Oliveira RC, Velardi M. A construção do corpo ideal no balé clássico: uma investigação fenomenológica. Rev. Bras. Educ. Fís. Esporte 2015; 29(3):439-452.

12. Moura KCF. Essas bailarinas fantásticas e seus corpos maravilhosos: existe um corpo ideal para a dança? [Dissertação]. [Campinas, SP]: Universidade Estadual de Campinas; 2001.

13. Hass NA, Garcia ACD, Bertoletti J. Imagem corporal e bailarinas profissionais. Rev. Bras. Med. Esporte 2010; 16(3):182-185.

14. Finco D. Relações de gênero nas brincadeiras de meninos e meninas na educação infantil. ProPosições 2003; 14(42):89-101.

15. Scott JW. Gênero: uma categoria útil de análise histórica. Educação \& Realidade 1995; 20(2):71-99.

16. Bento B. Na escola se aprende que a diferença faz diferença. Estudos Feministas 2011; 19(2):549-559

17. Graciano M. Homem - Mulher: por que polarizamos o sexo. Cad. Pesquisa Fundação Carlos Chagas 1978; (26):93-98.

18. Louro GL. Gênero, sexualidade e educação: uma perspectiva pós-estruturalista. Petrópolis, RJ: Vozes; 1997.

19. Guizzo BS. Identidade de gênero masculinas na infância e as regulações produzidas na educação infantil. Revista Àrtemis 2007; 6:38-48.

20. Assis MDP, Saraiva MC. O feminino e o masculino na dança: das origens do balé à contemporaneidade. Movimento 2013; 19(02):303-323.

21. Aquino SG, Schwartz RM. Influência do ballet de repertótio do século XIX no imaginário feminino. VII Jornada de Iniciação Científica; 2011; São Paulo; Universidade Presbiteriana Mackenzie.

22. Almeida DD. Identidade física, pessoal, institucional e espiritual: etnografia embodied de uma companhia de ballet [dissertação]. [Porto Alegre]: PUCRS; 2012.

23. Lopes AS. A imagem do feminino no balé clássico e na dança moderna na primeira metade do século XX. Educação, Gestão e Sociedade: Revista da Faculdade Eça de Queirós [Internet]. 2013; 3(12). [acesso em: 03 maio 2016]. Disponível em: http://www.uniesp.edu.br/Faceq/regs/downloads/ numero12/AimagemdoFeminino.pdf

24. Terra MR. O desenvolvimento humano na Teoria de Piaget [Internet]. [acesso em: 15 fev. 2016]. Disponível em: http://www.unicamp.br/iel/site/alunos/publicacoes/textos/d00005.htm

25. Bartolo P. Curso de qualificação para professores de Baby Class Ballet. Apostila, 2016.

26. Alves F. Introdução à psicomotricidade. Rio de Janeiro: Universidade Cândido Mendes; 2016. Apostila do curso de Pós Graduação Lato Sensu.

27. Oliveira PLT. O ballet clássico com psicomotricidade [dissertação]. [Rio de Janeiro]: Universidade Candido Mendes; 2016. 
28. Souza AAA. A prática pedagógica do balé clássico na educação infantil: revelando caminhos. Varzéa, SP: Fontoura; 2012.

29. Santos TM. Entre pedaços de algodão e bailarinas de porcelana: a performance artística do balé clássico como performance de gênero [dissertação]. [Porto Alegre]: UFRGS; 2009.

30. Arán M. O avesso do avesso: feminilidade e novas formas de subjetivação. Rio de Janeiro: Garamond; 2006.

Recebido: 20/4/2016

Revisado: 28/7/2016

Aceito: 23/8/2016 